\title{
Hydrophilic thiourea-modified poly(acrylonitrile-co-acrylic acid) adsorbent: preparation, characterization, and dye removal performance
}

\begin{abstract}
Poly(acrylonitrile-co-acrylic acid) was synthesized through redox polymerization reaction performed at $60^{\circ} \mathrm{C}$ under nitrogen gas by varying the feed ratio of acrylonitrile (AN) and acrylic acid (AA), and it was chemically modified with thiourea. The yield of polyacrylonitrile (PAN) and poly(AN-co-AA) samples were over 70\%. The unmodified and modified samples were characterized using FTIR, SEM, CHNS, zeta potential and BET analysis. Fourier transform infrared (FTIR) spectrometer, scanning electron microscope (SEM) and Zetasizer characterized the morphology and structures of thiourea-modified poly(acrylonitrile-co-acrylic acid). Successful introduction of acrylic acid in copolymer was confirmed by the appearance of $\mathrm{C}=\mathrm{O}$ at $1730 \mathrm{~cm}-1$ in its FTIR spectra. The polymer surface modification was accomplished by the total disappearance of $\mathrm{C} \equiv \mathrm{N}$ band from FTIR analysis and the appearance of new peaks at 3351-3349 cm-1 assigned to $\mathrm{N}-\mathrm{H} 2$ and $\mathrm{OH}$ groups, which confirmed successful incorporation of thiourea into prepared poly(AN-co-AA) chains. The average particle size of the prepared thiourea-modified poly(AN-co-AA) and poly(ANco-AA), respectively, was $308 \mathrm{~nm}$ and $300 \mathrm{~nm}$. CHNS elemental analysis revealed the percentage increments of carbon, hydrogen, nitrogen and sulfur components from unmodified to modified polymers. Zeta potential measurements were also inveterate the integration of thiourea, with modified poly(AN-co-AA) which was more negatively charged than the unmodified poly(AN-co-AA). The performance of adsorptive capacity of thiourea-modified poly(AN-co-AA) for cationic methylene blue and malachite green dyes as a case study revealed a better performance than that of poly(AN-co-AA) adsorbent. The results demonstrated that thiourea-modified poly(AN-co-AA) could be used as efficient adsorbents for cationic dye or pollutant removal from aqueous solution.
\end{abstract}

Keyword: Redox polymerization; Polyacrylonitrile; Modified poly(acrylonitrile-co-acrylic acid); Surface charge; Adsorptive capacity 